\title{
EXPERIMENTAL STUDIES OF SLOW STABLE BRITTLE CRACK-GROWTH IN POLYMETHYL-METHACRYLATE
}

\section{P.S. Theocaris}

Department of Theoretical and Applied Mechanics, The National Technical University of Athens, 5, Heroes of Polytechnion Avenue, Zographou, Athens 624, Greece

\begin{abstract}
A controlled crack growth was achieved in single edge-cracked specimens made of a high-molecular weight PMMA by regulating the crosshead speed of loading of the specimens by a computer-driven testing device. The crosshead speeds used during the tests were varied between $v_{s}=1 \times 10^{-7} \mathrm{~m} / \mathrm{s}$ and $1 \times 10^{-5} \mathrm{~m} / \mathrm{s}$.
\end{abstract}

It was shown that in this area of very slow quasi-static loading of brittle plexiglas specimens under conditions of plane stress the crack initiated at some critical value of loading, characteristic of the crosshead speed and almost independent of the initial crack length.

It was established that in the interval of crosshead speeds between $\mathrm{v}_{\mathrm{s}}=0.2 \times 10^{-6} \mathrm{~m} / \mathrm{s}$ and $\mathrm{v}_{\mathrm{s}}=0.6 \times 10^{-5} \mathrm{~m} / \mathrm{s}$ brittle cracks propagated always slowly with velocities of the order $\mathrm{c}=3$ to $5 \times 10^{-2} \mathrm{~m} / \mathrm{s}$. For lower or higher values of $\mathrm{v}_{s}$ than the lower or higher limits of this transition zone, fracture was typically brittle with high crack-propagation velocities. In the vicinity of the lower bound the velocity of the crack at the initiation zone strongly oscillated and then stabilized to some, almost constant velocity of the order of 5 to $10 \times 10^{-2} \mathrm{~m} / \mathrm{s}$, which was stable along the whole width of the specimen and only at the vicinity of the opposite boundary was reduced considerably oscillating again.

\begin{abstract}
As the crosshead speed $\mathrm{v}_{\mathrm{s}}$ was increasing beyond the stable low-velocity region, a two-step crack velocity region was appeared. The first step was manifested after the initiation of propagation of the crack, which took always low values, and a second step, where the crack-propagation velocity was increased considerably, tending to typical brittle-fracture velocities of the material. Oscillations of the velocity $c$ at the transition zones, or, in many cases all over the zone of slow propagation of the crack, indicated the unstable character of crack propagation, influenced by different stress raisers and especially by the opposite longitudinal boundary of the specimen.
\end{abstract}

Stress intensity factor values during crack propagation were remained always $\mathrm{K}_{\mathrm{I}}$-dominant and rather insenstitive to variation of $\mathrm{c}$, following similar trends as the variation of the crack propagation velocity.

\section{INTRODUCTION}

It has been well established during recent years that various molecular-weight polymethylmethacrylate samples present jumps of crack propagation velocity c at critical values of stress intensity factor $\mathrm{K}_{\mathrm{IC}}$. Döll (Ref.1) reports that high-molecular weight polymethylmethacrylate $\left(\mathrm{M}_{\mathrm{W}}=8 \times 10^{6}\right)$ at room temperature presents a jump in crack propagation velocity in the region of velocities $c$ between $c=0.1 \mathrm{~m} / \mathrm{s}$ to $c=100 \mathrm{~m} / \mathrm{s}$, depending on the conditions of testing. Döll (Ref.2) has studied the phenomenon and reports that the morphology of the fracture surface is changing, depending on the crack velocity. The phenomenon of appearance of various types of fracture surfaces was qualitatively related to crack propagation velocities by many investigators (see for example Ref.3).

The relation between the fracture toughness $\mathrm{K}_{\mathrm{IC}}$ and crack propagation velocity $\mathrm{c}$ was studied by Johnson and Radon (Ref.4) and simultaneously by Rosenfield and Kanninen (Ref.5). A composite graph, including the results of several investigations and covering a large range of crack propagation velocities, indicates that, for low crack velocities between $10^{-9} \mathrm{~m} / \mathrm{s}$ and $10^{-2} \mathrm{~m} / \mathrm{s}$ there is an almost constant fracture toughness of the material. But, for velocities $c$ higher than $10^{2} \mathrm{~m} / \mathrm{s}$ there is a continuous increase of fracture toughness with increasing velocity. However, in the zone of velocities between $c=10^{-2} \mathrm{~m} / \mathrm{s}$ and $c=10 \mathrm{~m} / \mathrm{s}$ an anomalous 
behavior of the material appears and this zone is neither well studied nor well understood.

The jumps in crack propagation velocities reported by Döll (Refs.1\& 2) belong to the zone for $\mathrm{c}>10^{2} \mathrm{~m} / \mathrm{s}$ and are strongly depended on the initial crack length $a$.

In this paper another anomalous zone of crack velocities between $10^{-2} \mathrm{~m} / \mathrm{s}$ and $10 \mathrm{~m} / \mathrm{s}$ was studied by applying the method of reflected caustics (Ref.7) in single edge cracked specimens under simple tension at room termperature $\left(t=25^{\circ} \mathrm{C}\right)$. Interesting results, concerning the various modes of fracture in this zone and the variation of crack velocity, were derived, useful for the in depth study of initiation- and arrest-modes of cracks in brittle materials.

\section{EXPERIMENTAL PROCEDURE}

For the study of the slow-dynamic crack propagation in polymethyl-methacrylate a series of tension specimens were used, which have all of them standard dimensions. The typical dimensions of the specimens were $0.200 \times 0.050 \times 0.002 \mathrm{~m}^{3}$ and all of them contained transverse edge cracks at midway of their length.

For the preparation of the cracks a thin rotatory saw of a thickness of $0.0003 \mathrm{~m}$ was first cutting an artificial crack of a length $a_{0}=0.010 \mathrm{~m}$. Then, a convenient metallic sharp-wedge of a maximum thickness of $0.00035 \mathrm{~m}$ was indenting the lips of the artificial crack so that the tip of this crack was advancing in the material by 0.002 to $0.003 \mathrm{~m}$ creating a real crack extension. This composite crack was further extended by submitting the specimen to a tensile deformation in a computer-driven INSTRON tester, working at a very slow crosshead speed of the order of $\mathrm{v}_{\mathrm{s}}=1 \times 10^{-6} \mathrm{~m} / \mathrm{s}$. In this way the already existing real crack was further extended by another 0.002 to $0.003 \mathrm{~m}$. By this meticulous preparation of the cracks in the specimens a real crack was assured in all specimens and the repeatability of results of the tests was satisfactory.

Another standard dimension, which was kept constant during all tests, was the overall length of the specimens between jaws which was $1_{\mathrm{s}}=0.120 \mathrm{~m}$.

For the slow dynamic tests of the PMMA cracked specimens a computer-driven INSTRON 8032 tester was used, capable of applying loads with the same accuracy and sensitivity in the range between $0.1 \mathrm{~kg}$ and $2.5 \times 10^{4} \mathrm{~kg}$. The smallest crosshead speed developed by the machine was $2 \times 10^{-8} \mathrm{~m} / \mathrm{s}$. A very sensitive load-displacement plotter, incorporated in the machine, recorded the applied loads and checked the overall deformations of the specimens.

For recording accurately the exact position of the crack tip at each instant and determining simultaneously the instantaneous value of the stress intensity factor the method of reflected caustics was used (Ref.7). With this method the exact position of the crack tip on the front and rear faces of the specimen were determined by the centers of the front and rear caustics. Since the velocities of crack propagation encountered in our tests were very low, much lower than the limit of $c / c_{1}=0.6$ where the dynamic caustic differs significantly from the respective static caustic ( $c_{1}$ is the longitudinal wave velocity for PMMA, which is $c_{1}=2,050 \mathrm{~m} / \mathrm{s}$ ), it can be accepted that there is no displacement and distortion of the caustics, due to the dynamic effect (Ref.8).

For the evaluation of the instantaneous values of the stress intensity factor the transverse diameters $D_{t}$ of the front and rear caustics were measured at each time instant. Since the rear-face caustic is always larger and yields more accurate results than the front caustic, all calculations of SIFs were made with the rear-caustic diameters.

It is worthwhile mentioning here that there were measured discrepancies in the values of SIFs determined from the rear- and the respective front-caustics, which may be explained by the phenomenon, frequently appearing in these tests, where the crack front was not always normal to the average lateral faces of the cracked plate, but a phenomenon of crack-front crawling appeared frequently, derived from the step-wise advancement of the slowly propagating cracks. However, this phenomenon is a complicated one and deserves a more thorough study, which is not included in this paper.

Since the cracks in this range of crosshead speeds were propagated very slowly it was not necessary to use complicated experimental setups for the recording of the crack propagation, including a Cranz-Schardin high-speed camera. In our experiments we have used a closed-1oop television circuit with a velocity of recording $v_{r}=2 \times 10^{-2}$ sec. A simultaneous recording of a digital chronometer with a sensitivity of $1 \times 10^{-2} \mathrm{sec}$ allowed the accurate recording of time lapse during each test. A two-channel Tektronix oscilloscope was completing the experimental arrangement.

The specimens were illuminated by a cw HN laser-beam impinging, through a system of lenses, allover the zone of propagation of the cracks. The reflected rays were received on a groundglass screen and the events on this reference screen were recorded in the video recorder. 


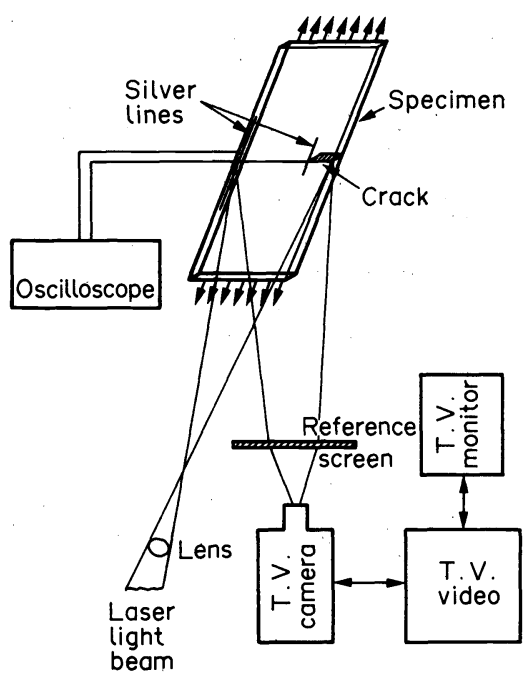

Fig. 1. The experimental set-up for slow crosshead speed tests in PMMA SENspecimens.

Fig.l presents schematically the experimental arrangement.

In the cases when the crack velocities overpassed the possibilities of recording of the abovedescribed setup, when the crosshead speeds were outside this critical zone of loading speeds, the average propagation velocity of the cracks was recorded by a system of two silvercontact circuits, which triggered two sparks with the initiation and complete fracture of the specimen without any delay. Thus, high propagation velocities in their respective zones were evaluated as average values of the respective lengths divided by the time interval between triggered sparks.

\section{RESULTS}

Zones of Different Propagation Behavior of the Crack. The first noticable result is that there is another zone of slow application of the external load where the typically brittle-fracture mode of PMMA passes through a transition from abrupt explosive mode of fracture to a very slow crack propagation, like a ductile rubbery-like fracture. This zone was not up-to-now detected and only Rosenfield and Kanninen (Ref.5) indicated some kind of anomaly at this zone.

This zone extends to crosshead speeds of the specimens between $v_{s}=2 \times 10^{-7} \mathrm{~m} / \mathrm{s}$ and $v_{s}=6$ to $8 \times 10^{-5} \mathrm{~m} / \mathrm{s}$. Outside this loading-speed interval, fracture of PMMA was typically brittle with crack-velocities much higher than the velocities encountered in the transition zone. We call these zones of a typically brittle mode of fracture as zones I and V (Fig.2) starting from lower crosshead speeds and increasing these speeds.

In-between these typically brittle zones there exists a transition zone III, (Fig.2), where the crack propagation velocities are very low of the order of $c=3$ to $5 \times 10^{-2} \mathrm{~m} / \mathrm{s}$. However, at the two extremities of this low-velocity zone there appear also two intermediate zones II and IV of transition of crack propagation velocity from a very high value to low one (zone II) and inversely from a low to a high value (zone IV).

Low-Intermediate Zone of Crack Propagation (Zone II). In zone II the trend of crack velocity is to initiate fracture, after some low-velocity oscillating zone, with a high brittle-1ike velocity, which is kept almost constant along the greater part of the width of the specimen and then to reduce this velocity to low oscillating values at the close vicinity of the opposite longitudinal boundary of the specimen, before complete failure of the specimen. This type of fracture is of the type of an unstable fracture, where the crack-propagation velocity at initiation and the end of the phenomenon oscillates, or is reduced due to the influence of obstacles, the main of which are the as-yet stationary mode of crack at the beginning, and the opposite boundary of the specimen at the end of propagation, which acts as a reflector of the stress waves emanating from the crack-tip during propagation, and also as crack-arrester.

Fig. 3 presents the crack-propagation velocity $c$ and the respective stress intensity factor versus the crack-length $a$ for the zone II. It is worth noting that after an initial oscillation of the crack propagation velocity, the values of c remained almost constant of the order of $c=2$ to $10 \times 10^{-2} \mathrm{~m} / \mathrm{s}$ and at the end of the phenomenon was always a typical reduction of crack propagation velocity, as well as of the value of SIF, due to the influence of the boundary. 


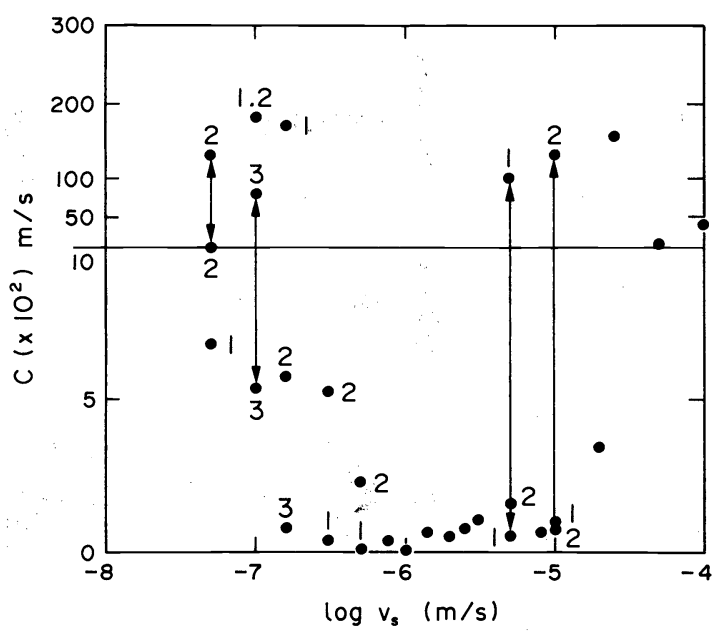

Fig. 2. Variation of the crack propagation velocity $c$ of PMMA SEN-specimens versus the crosshead speed of loading at the instability region defined by $10^{-8} \mathrm{~m} / \mathrm{s}<\mathrm{v}_{\mathrm{s}}<10^{-4} \mathrm{~m} / \mathrm{s}$.

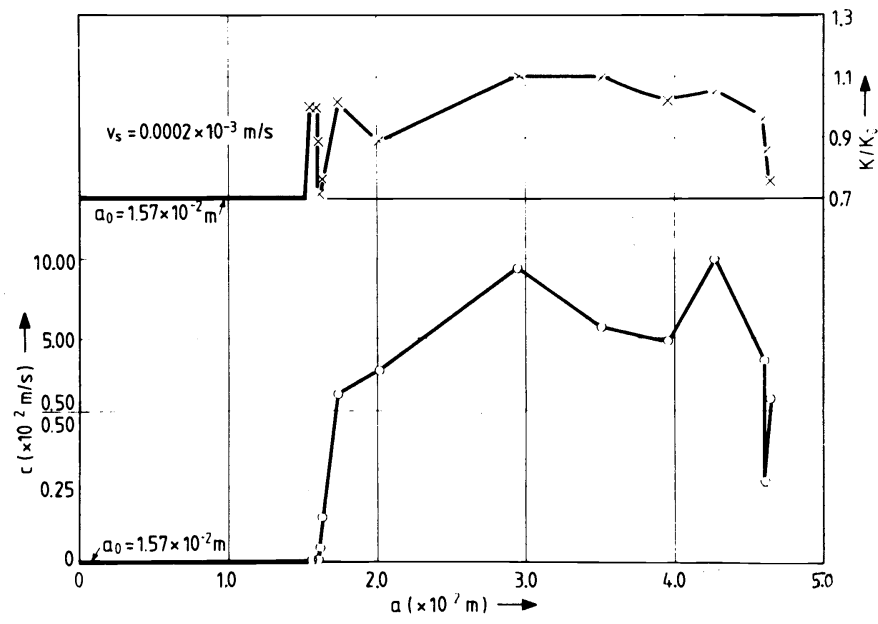

Fig. 3. Variation of the crack propagation velocity $\mathrm{c}$ and the stress intensity factor $\mathrm{K}_{\mathrm{I}} / \mathrm{K}_{0}$, normalized to its static value, versus crack length a for a crosshead speed of loading $\mathrm{v}_{\mathrm{s}}=2 \times 10^{-7} \mathrm{~m} / \mathrm{s}$.

Fig. 4 presents a series of photographs showing the form and size of caustics at various stations of crack propagation in this zone. It is clear from the instantaneous orientation of the caustics, as well as from the overall path of the cracks that, during all tests, only the $\mathrm{K}_{\mathrm{I}}$-mode of deformation was operative and mode-II was always zero.

Since in the zone II there is a two-step variation of the crack propagation velocity, that is an initial one, followed by a transition zone of oscillating velocity, and a final one before complete failure, typical tests represented in Fig. 2 are mapped with a double point at the same abscissa $v_{s}$ and connected with a double-arrow line. The values of the particular velocities c for each step correspond to their average values along the whole step.

Slow-Stable Crack Propagation Zone (Zone III). Fig.5 presents the variation of the crackpropagation velocity $\mathrm{c}$ and the stress intensity factor $\mathrm{K}_{\mathrm{I}}$ for the zone III, where the crack initiates and propagates steadily with a low velocity of the order of 3 to $5 \times 10^{-2} \mathrm{~m} / \mathrm{s}$. This zone III extends between crosshead speeds $v_{s_{\min }}=1 \times 10^{-6} \mathrm{~m} / \mathrm{s}$ and $v_{s_{\max }}=5$ to $6 \times 10^{-6} \mathrm{~m} / \mathrm{s}$.

The crack propagation velocities $c$ in this zone are almost stable with small fluctuations, due perhaps to the crawling phenomenon of the crack-front. However, some oscillations of velocity $c$ at the crack initiation period, and also at the end of fracture, due to the influence of the opposite boundary of the specimen, appeared. Besides these fluctuations the crack propagated always steadily from the beginning to the end of the phenomenon. 


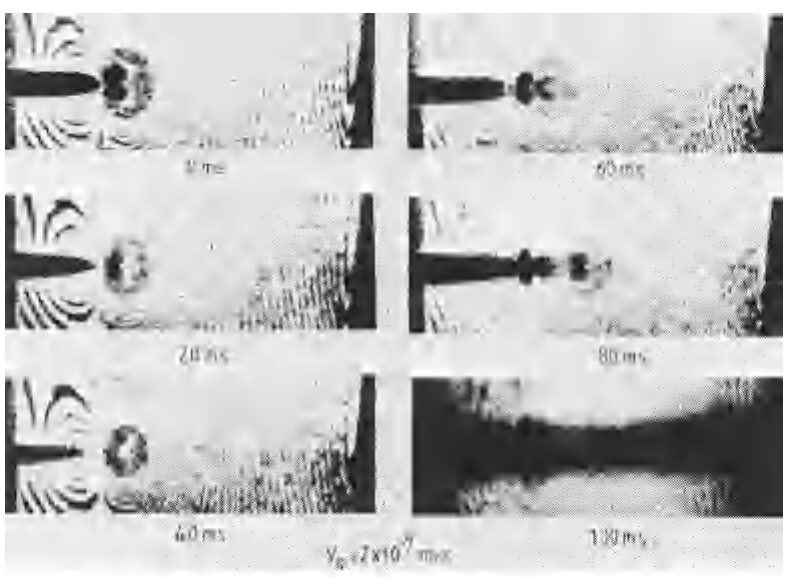

Fig. 4. A series of photographs of the caustics corresponding to different instants of the crack propagation in a PMMA SEN-specimen with $\mathrm{v}_{\mathrm{s}}=2 \times 10^{-7} \mathrm{~m} / \mathrm{s}$.

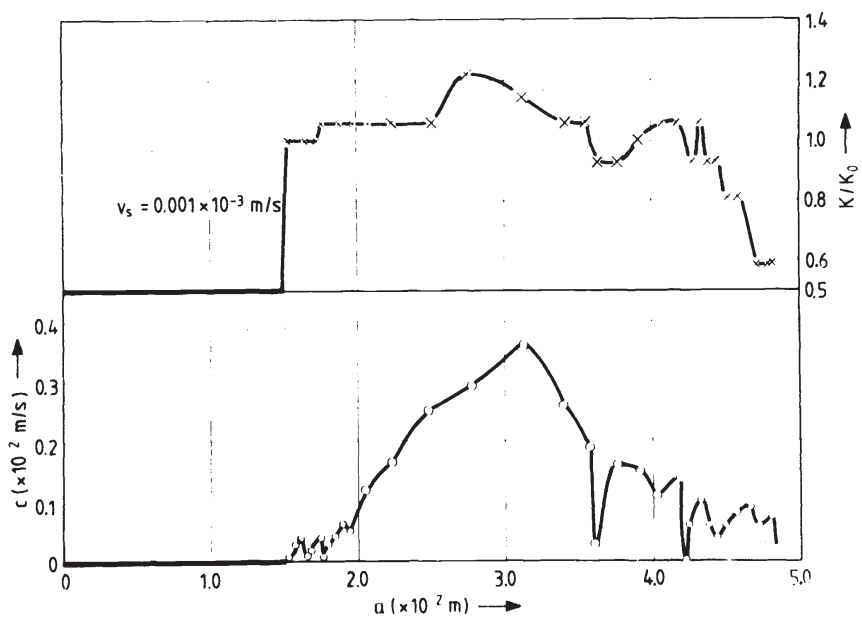

Fig. 5. Variation of the crack propagation velocity $\mathbf{c}$ and the stress intensity factor $\mathrm{K}_{\mathrm{I}} / \mathrm{K}_{0}$, normalized to its static value, versus crack length $a$ for a crosshead spee of loading $\mathrm{v}_{\mathrm{s}}=10^{-6} \mathrm{~m} / \mathrm{s}$.

Moreover, the values of average velocities $c$ in this zone were almost stable and they did not present a significant scattering.

Fig.6 presents a series of six photographs indicating the instantaneous positions of the propagating crack-tip and the respective caustic. Since the velocity $c$ for this region is almost stable with small oscillations at the beginning and the end of the phenomenon the caustics of almost equal size are spread regularly along the length of the specimen. A small deviation from the straight crack path may be explained by the eventual development of some bending as the crack progresses into the specimen.

High-Intermediate Zone of Crack Propagation (Zone IV). In the two-step intermediate zone IV, above the slow-velocity zone, the crack during initiation is unstable, its propagation velocity is strongly oscillating for a long interval and then stabilizes to an increasing value with time, until it approaches the opposite boundary of the specimen, where abruptly increases to a brittle-type velocity and the specimen fractures instantaneously. Similarly, the values of the stress intensity factor oscillate on the one side of its static value, until the abrupt propagation of the crack, for which it was not possible to evaluate $\mathrm{K}_{\mathrm{I}}$ since no caustic could be recorded in this interval.

Fig.7 presents the variation of the crack-propagation velocity and the stress intensity factor versus crack length $a$ for the zone IV, whereas Fig.8 shows a series of photographs with the instantaneous positions and shapes of the caustics at different crack-lengths. It is 

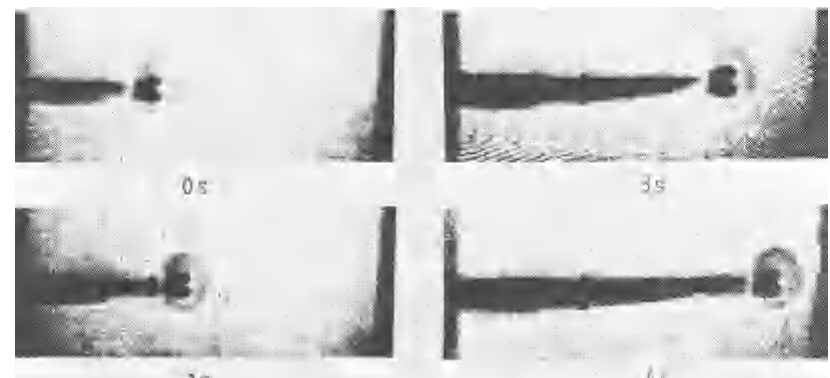

15
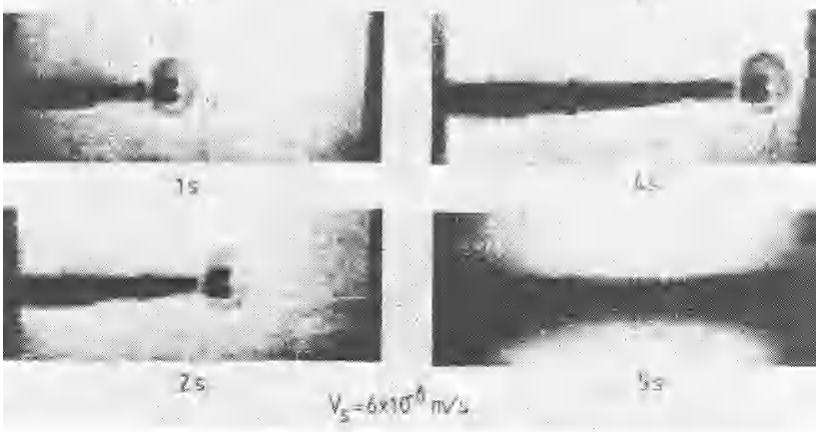

Le

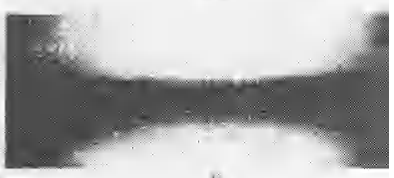

53

Fig. 6. A series of photographs of the caustics corresponding of different instants of the crack propagation in a PMMA SEN-specimen with $v_{\mathrm{s}}=6 \times 10^{-6} \mathrm{~m} / \mathrm{s}$.

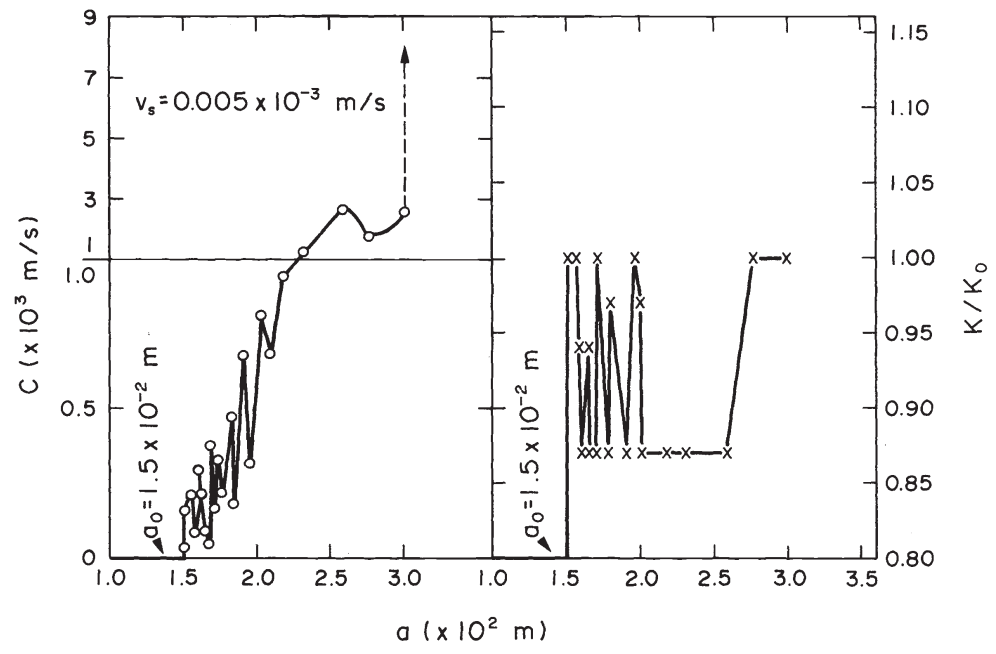

Fig. 7. Variation of the crack propagation velocity $\mathrm{c}$ and the stress intensity factor $\mathrm{K}_{\mathrm{I}} / \mathrm{K}_{0}$, normalized to its static value, versus crack length $a$ for a crosshead speed of loading $v_{s}=5 \times 10^{-6} \mathrm{~m} / \mathrm{s}$.

worthwhile indicating the reduction in size of both external and internal caustics during the period of loading, before initiation of propagation of the crack (Figs 8,1 to 4 ), the initiation of propagation with an simultaneous increase of the size of both caustics, while another caustic of large size was developed at the end of the artificial initial crack during the whole period of evolution of the fracture phenomenon.

Here, in this zone IV, the crack was always progressively accelerated, as it propagated, so that at the end of the event the situation was becoming unstable and the crack under the influence of the opposite boundary was escaping the influence of this transition zone yielding again a typical, rapidly propagating, brittle crack.

The variation of the $\mathrm{K}_{\mathrm{I}}$-stress intensity factor was following the fluctuations of the crack propagation velocity $\mathrm{c}$, as it is indicated in Fig.8. However, there was always a significant hysteresis in the development of the values of $\mathrm{K}_{\mathrm{I}}$, so that the fluctuations of this quantity were always insignificant.

Rapid Brittle Zones Outside the Transition Region. For crosshead speeds outside the transition region, that is for $v_{s}<1 \times 10^{-7} \mathrm{~m} / \mathrm{s}$ and $v_{s}>1 \times 10^{-5} \mathrm{~m} / \mathrm{s}$ the crack behaved like a typical brittle crack, rapidly propagating, with high velocities allover the specimen. However, at the initiation and incubation period there appeared always, at the beginning, fluctuations of the size of caustics during the stationary period of the crack. These fluctuations in size of the 


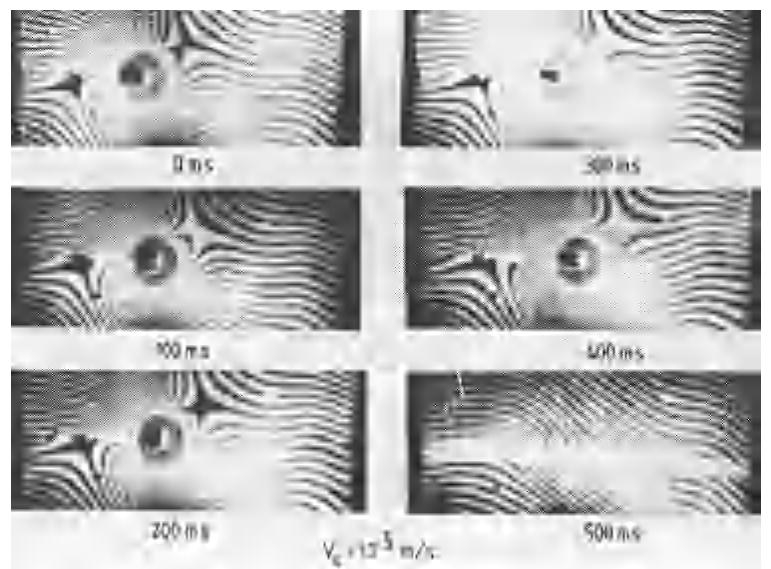

Fig. 8. A series of photographs of the caustics corresponding to different instants of the crack propagation in a PMMA SEN-specimen with $\mathrm{v}_{\mathrm{s}}=1 \times 10^{-5} \mathrm{~m} / \mathrm{s}$.

caustic were followed by fluctuations of the velocity c of the crack, when it was initiated and until it had stored enough energy to propagate stably with a high, typical for brittle fractures, velocity. However, the values of these velocities were not measured, needing a typical for high velocities detecting equipment and they were not included in the studies of this paper.

Fig.9 presents the variation of crack propagation velocity $c$ and the $\mathrm{K}_{\mathrm{I}}$-stress intensity factor for a typical brittle crack created with a cross-head speed at the upper-limit of the phenomenon. It is apparent from this figure that the velocity $c$ and the $\mathrm{K}_{\mathrm{I}}$-factor pass through an incubation zone of progressively increasing and fluctuating values, until an unstable, typically brittle, crack propagation is established.

In order to show the general trend of the instability of crack propagation velocity $c$ in this zone of crosshead speeds we have plotted the average values of $c$ for a series of experiments, where appeared only one step of velocity or two steps for the tests where a double average crack velocity was observed, versus the crosshead speed $v_{s}$.

Fig.2 presents this graph, where the double-step tests appeared with two points joined with a double-arrow ordinate and they are numbered with the same number. For a better showing of the details of the variation of $c$, a double scale for the ordinates was used. It is clear from this graph that outside this trough of reduction of crack propagation velocities, the values of $c$ are very large attaining the usual values of crack velocities in brittle fracture $(c>100 \mathrm{~m} / \mathrm{s})$.

In the instability zone, defined in the interval $5 \times 10^{-8}<v_{s}<5 \times 10^{-4}$, the velocity $c$ is reduced considerably attaining stable values at the bottom of the trough, equal to $c_{\mathrm{min}}=5 \times 10^{-3} \mathrm{~m} / \mathrm{s}$ and presenting the already described transition zones at both extremities of this zone.

It is also of interest remarking that although in this instability zone the velocity varied significantly for each and every value of $\mathrm{v}_{\mathrm{S}}$ the respective values of $\mathrm{K}\left(\mathrm{K}=\mathrm{K}_{\mathrm{I}}\right)$ remained at the average constant and approximately equal to its static value $\mathrm{K}_{0}$, defined from the initial crack length and the applied stress to each specimen.

Fig. 10 presents the variation of the values of $\mathrm{K}\left(\mathrm{K}_{\mathrm{I}} \equiv \mathrm{K}_{\mathrm{IC}}\right)$, normalized to its respective static value $\mathrm{K}_{0}$, versus the crack propagation velocity for various parametric values of the crosshead speed $v_{s}$. These values remain always constant, so that the $\mathrm{k} / \mathrm{K}_{0}$-ratio oscillates about unity.

Associated with this instability of velocity $c$ is a significant change in the texture of fracture. Rough surfaces appeared at slow propagation velocities and an intensification of roughness, was characteristic in the instability region. The slow brittle fractures presented a stick-slip behavior, according to which each crack-kink, consisting of a jump and an arrest event, was manifested by a crack-arrest line appearing on both fracture surfaces. These arrest lines presented a ridged appearance with the ridges manifested sequentially above and below the fracture plane in either halfs of the specimens.

Parallel evidence of the stick-slip phenomenon was manifested by the crawling phenomenon of the caustics during slow crack propagation, where the relative position of the front and rear caustics was changing with the internal caustic either advancing, or retarding, relatively to the external caustic. This phenomenon may be explained by the continuous changing of 


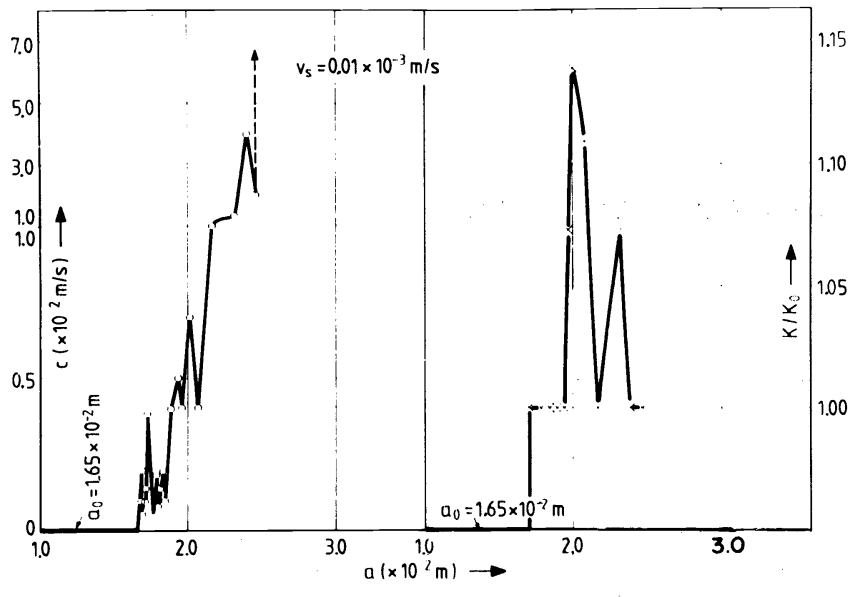

Fig. 9

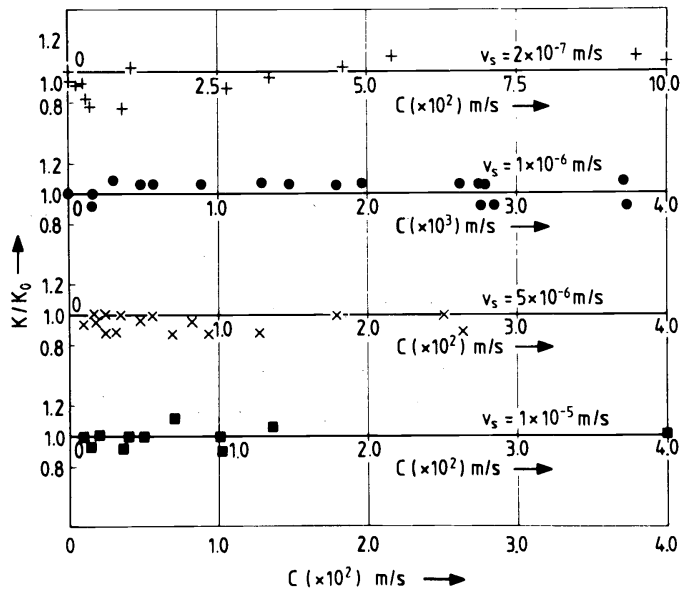

Fig. 10

Fig. 9. Variation of the crack propagation velocity $\mathbf{c}$ and the stress intensity factor $\mathrm{K}_{\mathrm{I}} / \mathrm{K}_{0}$, normalized to its static value, versus crack length $a$ for a crosshead speed of loading $v_{s}=10^{-5} \mathrm{~m} / \mathrm{s}$.

Fig. 10. Variation of the stress intensity factor as the crack propagates along the specimen, normalized to its respective static value, versus the crack propagation velocity for parametric values of the crosshead speed of loading in PMMA SEN-specimens.

orientation in an oscillatory mode of the crack-front, relatively to the middle plane of the cracked plate.

The mechanism, which accounts for this instability region in crack propagation velocity and which is better adapted to the details of variations of $c$ and $\mathrm{K}_{\mathrm{IC}}$, explains this phenomenon and similar ones, already studied (Ref.1) for PMMA at various regions of loading speed and temperature, as a thermal-shoftening effect due to a modification from isothermal to adiabatic conditions at the close vicinity surrounding the moving crack tip.

Although the temperature raise, occurring at the crazes developed at the vicinity of the crack tip, depends mainly on the crack propagation velocity, for slow fractures, of the order of a few centimeters per second, the temperature raise is insignificant at the average. This is because conduction of heat, away from the crack plane into the bulk polymer, prevents such a temperature increase. Then, this instability may be attributed to other mechanisms. However, it has been already stated for other regions of similar behaviour of PMMA at different loadingvelocity ranges (Ref.9\&10), that any small amount of heat, generated during the plastic deformation process, influences the already formed crazes around the crack tip, which are further splitted, as the crack propagates, and then partially healed thermally, because of a regional raise of temperature at their close vicinity.

Finally, it is worthwhile noting that, although a small increase in $\mathrm{K}_{\mathrm{IC}}$ was detected in the tests for values of crosshead speeds smaller than $0.01 \mathrm{~m} / \mathrm{s}$, in the instability region $\mathrm{K}-\mathrm{values}$ fluctuated about steady-state values with a variation of the crack propagation velocity, but they remained in the average constant and equal to their corresponding static values, with a tendency to decrease with increasing crosshead speeds. This phenomenon lasted until they rapidly increased in an abruptly rising curve of $K_{I}=f(c)$ for crosshead speeds beyond the limit of $\mathrm{v}_{\mathrm{s}}=10^{-4} \mathrm{~m} / \mathrm{s}$ and a crack propagation velocity $\mathrm{c}=10^{2} \mathrm{~m} / \mathrm{s}$.

\section{ACKNOWLEDGEMENTS}

The author expresses his gratitude for the assistance offered by Messrs C. Spyropoulos and A. Koutsambessis during the execution of the experiments contained in this paper.

\section{REFERENCES}

1. W. Dö11, JnI. Mat. Res. 10, pp.935-942 (1975).

2. W. Dö1l and G.W. Weidmann, Ji2l. Mat. Res., 11, pp.2348-2350 (1976).

3. B. Cottere11, Appl. Mat. Research, 4, pp.227-232 (1965).

4. F.A. Johnson and J.C. Radon, Engng. Fracture Mech., 4, pp.555-576 (1972).

5. A.R. Rosenfield and M.F. Kanninen, Jnz. Macromol. Sci. (Physics), B7(4), pp.609-631 (1973).

6. G.P. Marchall, L.H. Coutts and J.G. Williams, Jnl. Mat. Res. 9, pp.1409-1419 (1974).

7. P.S. Theocaris, Mechanics of Fracture, Vol.VII, G.C. Sih Editor, M. Nijhoff, Hague, Chapt. 3, pp.189-252 (1980).

8. P.S. Theocaris and G. Papadopoulos, Engng. Fract. Mech, pp.683-698 (1980).

9. J.G. Williams, Appl. Mat. Res., 4, pp.104-112 (1965).

10. J.G. Williams, Inter. JnI. Fract. Mech., 8, pp.393-401 (1972). 